\title{
Extracorporeal Septoplasty for anterior septal deviation and deviated nose
}

\author{
Brihaspati Sigdel* iD \\ Department of Otolaryngology and Head and Neck Surgery, Gandaki Medical College, Pokhara, Nepal
}

\begin{abstract}
Background: Deviated nose and septum is challenging, which results in functional and cosmetic problems. It blocks the nose and makes person ugly. The classical septoplasty approach becomes unsuitable for such severe deviations. Extracorporeal septoplasty is a surgical technique for correcting a severely deviated nasal septum, which also corrects the aesthetic part of the nose. The objective of this study was to describe extracorporeal septoplasty for Deviated nose and anterior septal deviation. Methods: A prospective observational outcome study was done in patients with Deviated nose and anterior septal deviation who underwent extracorporeal septorhinoplasty. Preoperative and postoperative evaluation was performed using a photographs, computerized tomography (CT) scan, and Nasal obstruction symptoms evaluation scale. Results: A total of 38 consecutive patients were enrolled, out of which majority were male $(24,63.2 \%)$ with only $14(36.8 \%)$ female. The ratio of male female was 1.7:1. All the subjects had deviated nasal septum. Among these, nose deviation was externally noticeable in 20 (52.6\%) cases, whereas in remaining cases it was inconspicuous. There were 21(55.3\%) patients where Nasal Septum was deviated to the right side followed by $17(44.7 \%)$ with left side deviation. There was a significant improvement in mean nasal obstruction symptoms evaluation postoperatively ( 71.2 versus 22.7 with $p$ value equal to 0.01 ). According to the pre and postoperative photographs 17(44.7\%) patients had good improvement, nine (23.6\%) showed excellent improvement and the result was fair in six (15.7\%) patients. Conclusions: Extracorporeal septoplasty is effective in improving both nasal airway function and aesthetics in patients with severe Nasal Septal deviation.
\end{abstract}

Key words: Deviated nose, Extracorporeal septoplasty, Rhinoplasty.

\section{Correspondence to:}

Dr. Brihaspati Sigdel

Associate Professor and Head of Department

Department of Otolaryngology \& Head and Neck Surgery

Gandaki Medical College, Pokhara, Nepal

E-mail: brihassig1@gmail.com

Submitted: July 17, 2020

Accepted: November 1, 2020

To cite: Sigdel B. Extracorporeal Septoplasty for anterior septal deviation and deviated nose. JGMC Nepal. 2020;13(2):144-8.

DOI: 10.3126/jgmcn.v13i2.30145

\section{INTRODUCTION}

Deviated nose and anterior septal deviation are some of the challenging conditions. it gives functional and aesthetic problems to patients. ${ }^{1}$ In some patients, the causes of nasal airway obstruction include narrow nasal valve and high septal deflection. It may be associated with a deviated nose and inferior turbinate hypertrophy. However, standard septoplasty is inadequate in such cases of severe anterior septal deviation. ${ }^{2}$, ${ }^{3}$ Furthermore, the septum in anterior septal deviation is often accompanied by a narrow valve angle, Rhinoplasty alone will not address the functional problem to patients. ${ }^{4}$ Although, Inferior turbinoplasty with conventional septoplasty will improve nasal function but will not address aesthetic issues. ${ }^{5}$ Additionally, Placement of spreader grafts has been well described, however, this technique alone does not address significant deviation of the anterior-caudal nasal septum. ${ }^{6}$

Extracorporeal septoplasty is a surgical technique for correcting a severely deviated nasal septum and also corrects the 
aesthetic part of the nose. In such a situation it needs fixation of quadrangular cartilage and nasal bone (keystone area). ${ }^{7}$

Therefore, the procedure to modify extracorporeal septoplasty with keystone region fixing and to do osteotomy to correct nasal bone was planned. Through ECS, the entire septum must be detached, reshaped, and re-implanted back into its original position. It stabilizes by fixing quadrangular cartilage at the keystone region with nasal bone, and medial crura of upper lateral cartilage. It was also affixed in Maxilla's anterior spine through making a hole on it by use of nylon 5-0 suture.

The objective of this study was to evaluate the quality of life and to provide cosmetic and functional outcomes by modified extracorporeal septoplasty technique in anterior septal deviation and deviated nose.

\section{MATERIALS AND METHODS}

The study was conducted at Gandaki Medical College Teaching Hospital, Pokhara, from July 2017 to June 2019. This study was approved by the Institutional ethical committee (GMC IEC Ref No.01-03-2074). Patients of at least 18 years of age with symptoms of nasal obstruction since one-year duration and anterior nasal deviation on examination were included. We also looked at the status of external nose deviation and inferior turbinate hypertrophy. Patients with a history of active nasal disease, atrophic rhinitis were excluded from this study.

Consent was taken from all patients. Preoperative photographs (frontal view, lateral, and basal view) were taken from the patients (figure.1 A, B, C) and a Computerized tomography scan was done (Figure 2).

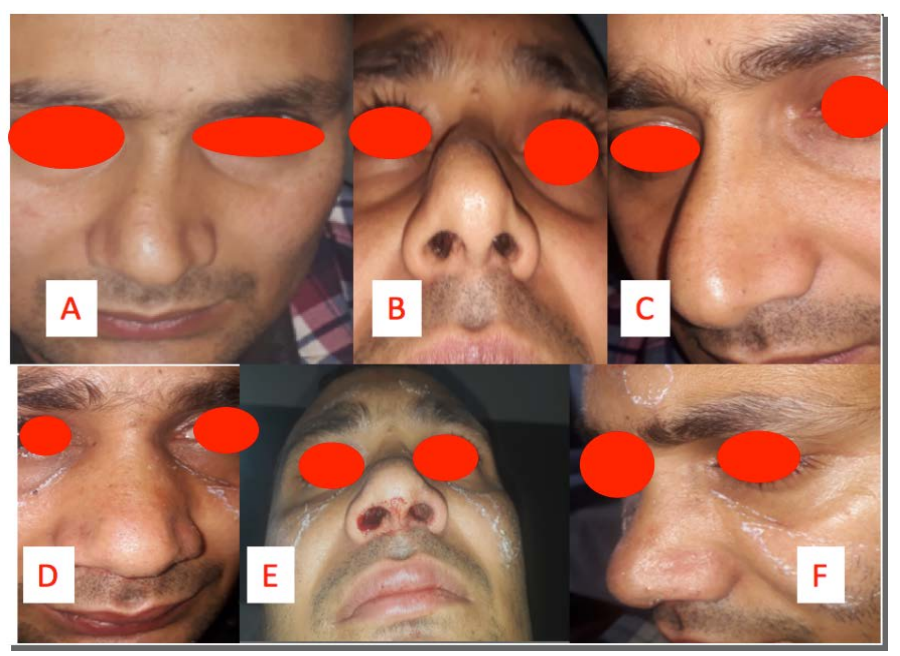

Fig 1: Preoperative evaluation of deviated nose A. Frontal B. Basal C. Lateral view Postoperative evaluation. D. frontal, E. Basal F. Lateral view

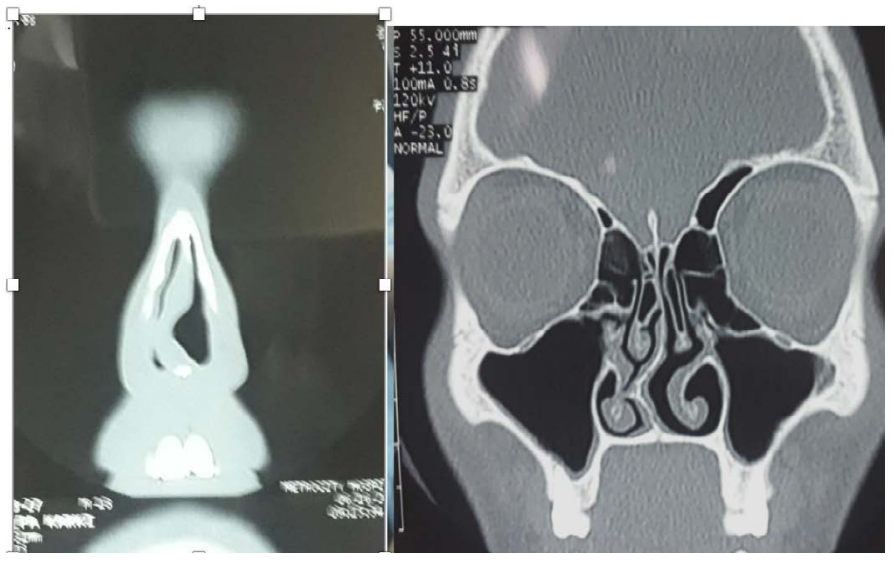

Fig 2: CT scan paranasal coronal view showing marked deviation of anterior septum toward right.

All the patients were treated with perioperative intravenous antibiotics. They were given ceftriaxone 1 to 2 gram or clindamycin 600 to 800 milligram, if the patient is allergic to penicillin, and administered according to the patient's body weight. Antibiotics therapy was continued postoperatively in prophylactic doses with cefpodoxime (Cepox) 200 milligram BD per day for one week.

\section{Surgical Technique}

Traditional septoplasty technique is inadequate in case of severe deviation of the nose and anterior nasal septum, because it cannot provide support to the lower two-third of the cartilaginous part of the nose. Removing this without appropriate reconstruction results in a nasal collapse.

The septum was exposed through the hemitransfixion incision. Flap was elevated from the concave side of deviated nasal septum by using hook and cautery rather than using Killian speculum. The caudal border of the quadrilateral cartilage was exposed by continuing dissection up to the nasal spine area (Figure $3 \mathrm{~A}$ ).

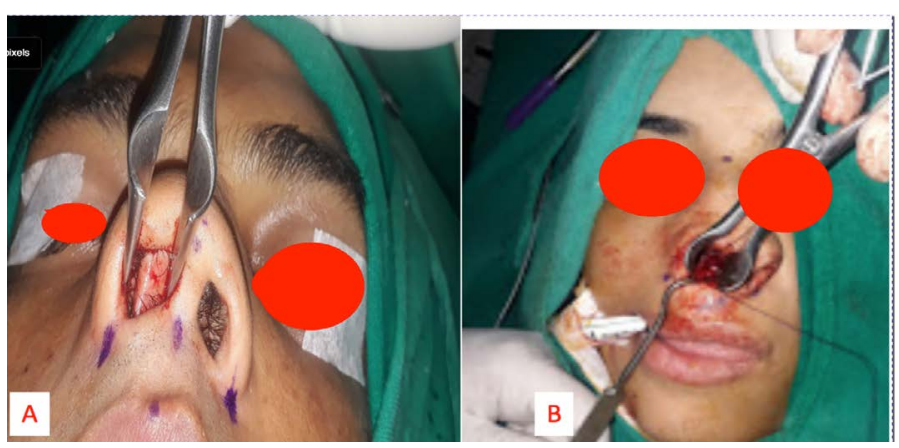

Fig 3: A. Deviated anterior septum, B. intraoperative pic 5-0 nylon fixed neoseptum in key stone area

The bilateral submucoperichondrial flap was elevated. The septum was freed from the caudal and dorsal border. The 
entire quadrilateral cartilage was taken out and reconstructed into an L shaped frame or other desired framework and kept back into its position (Figure 4). Then it was stabilize by fixing it into two areas. First at the keystone region with nasal bone, medial crura of upper lateral cartilage above and Maxilla's anterior nasal spine below by 5-0 nylon suture (figure 3B)

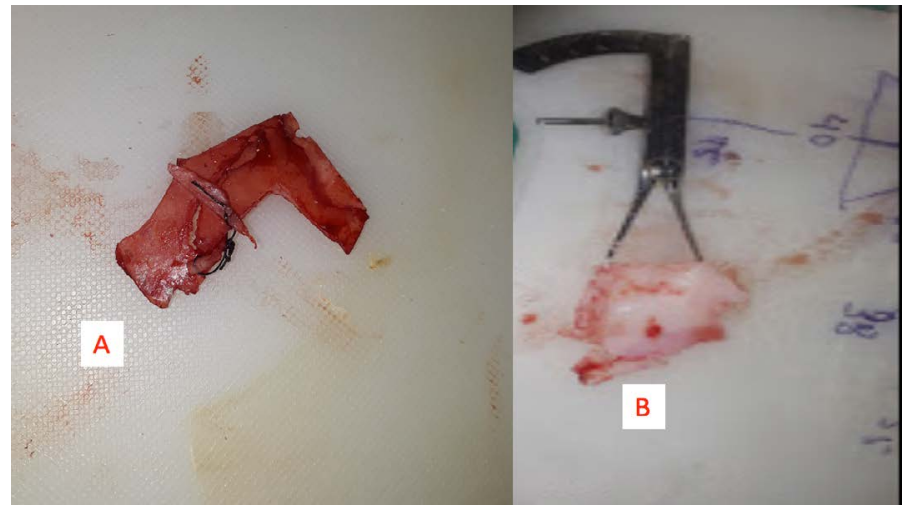

Figure 4: A. L strut neoseptum, B. measuring of quadrangular cartilage.

Sometimes Spreader grafts were also prepared from the remaining nasal septum and are placed unilaterally or bilaterally, and fixed with the septum with horizontal mattress suture. Osteotomies (lateral, medial, intermediate, and superior) were given whenever required. Upper lateral cartilages were attached to the graft-septum complex. The mucoperichondrial flap was reposited. The columellar incision site was closed. Merocele pack was kept in both nasal cavities and the nasal cast was applied. The Merocele pack was removed after 72 hours. The nasal cast was removed after 7 days.

Patients who have inferior turbinate hypertrophy were treated with endoscopic turbinoplasty using cautery or microderider technique.

NOSE scale was used to assess disease-specific Quality of Life (QOL) and is scaled from 0 to 100, with higher scores meaning more severe nasal obstruction. ${ }^{8}$ Baseline Nose scores were obtained at the preoperative visit. Follow-up NOSE scores were obtained at the post-operative visit.

The NOSE scale is used to assess disease-specific Nose Score (Table 1)

$0=$ not a problem

$1=$ very mild problem

$2=$ moderate problem

3 = fairly bad problem

$4=$ severe problem
Table 1: Nasal obstruction symptom evaluation (NOSE) Score

\begin{tabular}{ccccc}
\hline $\begin{array}{c}\text { Not a } \\
\text { problem }\end{array}$ & $\begin{array}{c}\text { Very mild } \\
\text { problem }\end{array}$ & $\begin{array}{c}\text { Moderate } \\
\text { problem }\end{array}$ & $\begin{array}{c}\text { Fairly bad } \\
\text { problem }\end{array}$ & $\begin{array}{c}\text { Severe prob- } \\
\text { lem }\end{array}$ \\
0 & 1 & 2 & 3 & 4 \\
0 & 1 & 2 & 3 & 4 \\
0 & 1 & 2 & 3 & 4 \\
0 & 1 & 2 & 3 & 4 \\
0 & 1 & 2 & 3 & 4 \\
\hline
\end{tabular}

Assessment of deviation improvement was done by comparison between the preoperative and postoperative photographs. According to this, outcomes were classified as $0=$ no change $1=$ fair, 2 = good, $3=$ excellent

The subjective satisfaction of patients was classified as excellent, good, fair, or poor by the use of questionnaires answered at office visits or in telephone interviews by patients.

Post-operative histories were reviewed to assess complications including infection, post-operative deformity (for example, saddling or notching), recurrence of deviation, and loss of tip support or projection.

\section{Statistical analysis}

All data entered in the Excel spreadsheet. This data was fed into SPSS version 26. Percentage and mean were calculated by using frequency statistics. Disease-specific quality of life i.e. Nose score compared pre- and post-operative value by paired T-test.

\section{RESULTS}

This study includes 38 consecutive patients with deviated nasal septum, who also had nasal functional and aesthetic complaints, with an age range between 18 to 40 years. The mean age was $24.7 \pm 6.26$ years. $24(63.2 \%)$ patients were below 25 years of age followed by 11(28.8\%) between 26 to 35 years of age. Out of 38 patients, male predominated females with $24(63.2 \%)$ and $14(36.8 \%)$, respectively. The male to female ratio was 1.7:1. Externally visible deviated nose found in 20(55.3\%) cases. Anterior nasal septum was deviated to the right side in $21(55.3 \%)$ and left side in $17(44.7 \%)$ cases. Deviated nasal septum with anterior dislocation was found in $17(44.7 \%)$ cases. Inferior turbinate hypertrophy was found in $6(15.8 \%)$ and concha bullosa in $2(5.26 \%)$ of cases. Septorhinoplasty was done in 23 (60.5\%) followed by septoplasty in 13(34.2\%) as shown in Table 2 . 
Table 2: Types of extracorporeal septoplasty

\begin{tabular}{lc}
\hline Type of extracorporeal septoplasty & No. of cases (\%) \\
Septorhinoplasty & $20(52.6)$ \\
Septoplasty & $10(26.3)$ \\
Septorhinoplasty \&Turbinoplasty & $3(7.9)$ \\
Septoplasty with Turbinoplasty & $3(7.9)$ \\
Septoplasty with the removal of the lateral & $2(5.3)$ \\
lamella of concha bullosa & $38(100)$ \\
\hline
\end{tabular}

While comparing Pre and postoperative photographs of patients, $17(44.7 \%)$ were found to have good improvement, $9(23.6 \%)$ showed excellent improvement and 6(15.7\%) showed a fair result. The anteroposterior photographic view was found to be better in the majority of the patients.

The patient satisfaction was excellent in 20 (52.6\%) of patients, good in $12(31.8 \%)$, and fair in $6(15.8 \%)$ of patients.

NOSE scale was used to assess disease-specific QOL. The patient showed improvement in nasal function after extracorporeal septoplasty which was statistically significant (Table. 3)

Table 3: Preoperative and postoperative NOSE Score

\begin{tabular}{lccc} 
& Mean & Standard Deviation & P-value \\
Pre-operative & 71.2 & 7.7 & 0.001 \\
Post-operative & 22.7 & 6.1 & \\
& & & \\
\hline
\end{tabular}

Out of 38 patients, 6 complained of pain at the tip of the nose. One patient had a wound infection. Saddling and recurrence were not seen during the follow-up period.

\section{DISCUSSION}

Correction of the severely deviated nasal septum with nasal airway obstruction and external deformity has been recognized for more than 50 years. ${ }^{1}$ It is important to address each issue separately in case of anteriocaudal septal deviation to get aesthetic and functional results. This can be solved by extracorporeal septoplasty, rhinoplasty, and turbinoplasty. Numerous surgical techniques have been proposed for deviated nasal septum. Deviated bony pyramids can be corrected using several osteotomy methods. In severe deviation of Antero-caudal septal cartilage, extracorporeal septoplasty is effective., ${ }^{9,10}$

Gubisch $^{11}$ had done more than 3000 extracorporeal septal reconstructions throughout the three-decade with minimal minor complications. We have to focus on both functional and aesthetic components of the nose; extracorporeal septoplasty with rhinoplasty addresses both components. For the functional purpose, any intranasal abnormality like inferior turbinate hypertrophy, the correction was done with inferior turbinoplasty

Septorhinoplasty is a better option for those patients with the most deviated external nose which we performed in $23(60.5 \%)$ cases. According to this study, extracorporeal septorhinoplasty was the best choice for the severely deviated nose which was similarly found in the study by Gubisch et al. ${ }^{12}$

Technique wise it should be very meticulous. Hook and mac dyne cautery tip in a low cautery setting was used to give caudal incision. Flap was raised from the concave side of the deviated nasal septum. Fixing at anterior nasal spine and crest of the maxilla was utmost importance in decreasing the saddling of the nose. Nylon 5-0 suture was used for this purpose. Although permanent sutures, it has the theoretical risk of suture extrusion or infection. Permanent sutures are not affected by the local environment and generally maintain their position and the level of structural support. ${ }^{13}$ The various modifications have been described like barber suturing for spreader graft ${ }^{14}$ and anterior septal reconstruction. ${ }^{2}$ All these modifications lead to decreased complications of the procedure.

We did not get any revision surgery in our study. This procedure can be carried out in situations where adequate craniocaudal septal cartilage is not available by harvesting rib cartilage. Nose score showed the subjective improvement of patients with statistically significant result as seen in one of the study. ${ }^{10}$ The complication rate in our study was $1(2.6 \%)$. The patient developed wound infection. Matt and Mobly ${ }^{15}$ also had complication in 2(4\%) patients.

\section{CONCLUSION.}

Extracorporeal septoplasty is an important surgical option for the correction of the markedly deviated nasal septum. Rhinoplasty techniques can be implemented in the same setting. The fixation of neo septum in the nasal spine and dorsal border with upper lateral cartilage is essential. With these procedures, improvement of Quality of life along with the aesthetic and functional of the nose can be maintained.

\section{REFERENCES}

1. Suh MK, Jeong E. Correction of deviated nose. Arch Craniofac Surg 2018;19:8593. DOI: 10.7181/ acfs.2018.01914

2. Most SP. Anterior Septal Reconstruction: Outcomes After a Modified Extracorporeal Septoplasty Technique. Archives of Facial Plastic Surgery 2006; 8: 202-7. DOI: 10.1001/archfaci.8.3.202. 
3. Bloching MB. Disorders of the nasal valve area. GMS Curr Top Otorhinolaryngol Head Neck Surg 2007;6: DOI: 07. 2007/01/01

4. Parrilla C, Artuso A, Gallus R, Galli J, Paludetti G. The role of septal surgery in cosmetic rhinoplasty. Acta Otorhinolaryngol Ital 2013;33:146153.2013/07/16

5. Becker DG, Ransom E, Guy C, Guy C, Bloom J. Surgical Treatment of Nasal Obstruction in Rhinoplasty. Aesthetic Surgery Journal 2010;30:347378. DOI: $10.1177 / 1090820 \times 10373357$

6. Samaha M, Rassouli A. Spreader graft placement in endonasal rhinoplasty: Technique and a review of 100 cases. Plast Surg (Oakv) 2015;23:252-4. DOI: 10.4172/ plastic-surgery.1000944

7. Kim CH, Jung DH, Park MN, Yoon JH. Surgical anatomy of cartilaginous structures of the Asian nose: clinical implications in rhinoplasty. The Laryngoscope 2010;120:14919. DOI: 10.1002/lary.20895 PMID: 20229583

8. Kahveci OK, Miman MC, Yucel A, Yucedag F, Okur E, Altuntas A. The efficiency of Nose Obstruction Symptom Evaluation (NOSE) scale on patients with nasal septal deviation. Auris Nasus Larynx 2012;39:275-9. DOI: 10.1016/J.ANL.2011.08.006 PMID: 21885221

9. Ghaisas V, Parab SR. Role of Extracorporeal Septoplasty in Deviated Noses. Indian J Otolaryngol Head Neck
Surg 2015;67:205-9.2015/09/26. DOI: 10.1007/ s120700150892x

10. Jang YJ, Kwon M. Modified Extracorporeal Septoplasty Technique in Rhinoplasty for Severely Deviated Noses. Annals of Otology, Rhinology \& Laryngology 2010;119:331-5. DOI:10.1177/000348941011900510

11. Gubisch W. Extracorporeal septoplasty for the markedly deviated septum. Archives of facial plastic surgery 2005;7:218-26. DOI: 10.1001/archfaci.7.4.218

12. Gubisch W. Treatment of the scoliotic nose with extracorporeal septoplasty. Facial Plast Surg Clin North Am 2015;23:11-22. DOI: 10.1016/j.fsc.2014.09.002

13. Kadakia S, Ovchinsky A. Comparison of Permanent Versus Absorbable Suture in the Tongue-in-Groove Technique in Endonasal Rhinoplasty. The American Journal of Cosmetic Surgery 2016;33:91-95. DOI:10.1177/0748806816644907

14. Rosen AD. Use of Barbed Sutures for Fixation of Spreader Grafts in Rhinoplasty: A Novel Technique. Biomedical Journal of Scientific \& Technical Research 2017;1. DOI: 10.26717/bjstr.2017.01.000590

15. Wilson MA, Mobley SR. Extracorporeal Septoplasty: Complications and New Techniques. Archives of Facial Plastic Surgery 2011;13:85-90. DOI: 10.1001/ archfacial.2011.5 